\title{
HOÀN THIỆN QUY TRÌNH XỬ LÝ CÁC DŨ LIỆU TRỌNG LỰC ĐỂ XÂY DỰNG CƠ SỞ DŨ LIỂU DI THƯỜNG TRỌNG LỰC QUỐC GIA Ở VIẸTT NAM
}

\author{
HÀ MINH HOÀ \\ Viện Khoa học Đo đạc và Bản đồ
}

\section{Tóm tắt:}

Bài báo khoa học này trình bày các kết quả nghiên cứu trên thế giới và đề xuất bổ sung vào các tiêu chuẩn quốc gia về trọng lực chi tiết các nội dung liên quan đến việc hiệu chỉnh dị thường không khí tự do bởi các số hiệu chỉnh do khối lượng vật chất khí quyển và khối lượng vật chất địa hình giữa mặt địa hình thực và mặt địa hình trung bình. Ngoài ra, bài báo này đề xuất sử dụng phương pháp tính toán số hiệu chỉnh Faye theo tích phân lăng trụ khi tính đến cấu trúc của các mô hình số độ cao độ phân giải cao hiện nay.

\section{1. Đặt vấn đề}

Trong tài liệu (Quy định đo trọng lực chi tiết) đã quy định các dạng dị thường trọng lực như dị thường trọng lực không khí tự do (thường được gọi tắt là dị thường không khí tự do), dị thường trọng lực Faye (thường được gọi tắt là dị thường Faye), dị thường trọng lực Bouguer (thường được gọi tắt là dị thường Bouguer). Lý thuyết về các dạng dị thường trọng lực nêu trên đã được trình bày chi tiết trong tài liệu (Hà Minh Hòa (2014)). Dị thường Faye tại một điểm đo trọng lực nhận được từ dị thường không khí tự do nhờ số hiệu chỉnh bề mặt đất (hay còn gọi là số hiệu chỉnh Faye) để loại bỏ ảnh hưởng của khối lượng vật chất địa hình lồi lõm xung quanh so với mặt phẳng nằm ngang đi qua điểm trọng lực. Đối với phương pháp xấp xỉ mặt phẳng, trong các tài liệu (Moritz, H. (1980); Forsberg $R$. (1984)) đã đưa ra công thức xác định số hiệu chỉnh bề mặt đất ở dạng sau:

$$
\delta g_{F}=\frac{G \cdot \sigma_{c r}}{2} \cdot \iint_{\omega} \frac{\left(H^{\gamma}-H_{P}^{\gamma}\right)^{2}}{r^{3}} \cdot d \omega,
$$

ở đây $\mathrm{G}$ - hằng số trọng trường Newton; $\sigma_{c r}$ - mật độ vật chất của lớp vỏ Trái đất

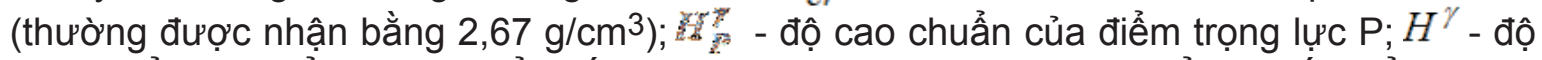
cao chuẩn của điểm chạy (điểm lấy tích phân); $r$ - khoảng cách từ điểm $\mathrm{P}$ đến điểm chạy; $\omega$ - vùng lấy tích phân.

Theo quy định, đối với vùng đồng bằng và trung $\mathrm{du}$, bán kính vùng lấy tích phân bằng $50 \mathrm{~km}$, còn đối với vùng núi - $200 \mathrm{~km}$.

Do ở Việt Nam sử dụng hệ độ cao chuẩn, nên các dữ liệu dị thường trọng lực được sử dụng chủ yếu để tính toán các giá trị dị thường độ cao (độ cao quasigeoid) phục vụ việc xây dựng mô hình quasigeoid quốc gia độ chính xác cao. Chúng ta không quan tâm đến việc tính toán độ cao geoid để phục vụ việc xây dựng mô hình geoid quốc gia độ chính xác cao. Do đó các giá trị dị thường Bouguer chủ yếu được sử dụng để nội suy chêm dầy các giá trị dị thường Faye (hoặc dị thường không khí tự do) ở các khu vực có ít các dữ liệu trọng lực khi tính đến sự thay đổi tương đối đồng đều của các giá trị dị thường Bouguer. 
Đối với lĩnh vực Địa chất, các giá trị dị thường Bouguer được sử dụng để nghiên cứu các cấu trúc sâu của vỏ Trái đất.

Về mặt lý thuyết, các giá trị dị thường trọng lực được sử dụng để giải quyết bài toán biên hỗn hợp của Trắc địa vật lý. Đối với cách tiếp cận của Molodenxkii M.X., mặt biên là mặt telluroid, nhưng thực tế bài toán biên hỗn hợp được giải quyết trên mặt vật lý Trái đất. Theo quy định, để các giá trị dị thường trọng lực là các hàm điều hòa và là các hàm giải tích sao cho chúng có các đạo hàm riêng các bậc trên mặt biên và trong không gian ngoài mặt biên, các khối lượng vật chất không được tồn tại trên mặt biên.

Theo các tài liệu (Moritz H. (1984); NGA.STND.0036_1.0.0_WGS84; Parametry Zemli 1990 (PZ-90.11)), các hằng số trọng trường địa tâm GM của các ellipsoid quy chiếu quốc tế như GRS80, WGS84, PZ - 90.11 đều bao gồm các khối lượng vật chất khí quyển. Do đó chúng ta bắt buộc phải loại bỏ ảnh hưởng của khối lượng vật chất khí quyển trong các giá trị dị thường không khí tự do. Đây là vấn đề đầu tiên cần giải quyết để hoàn thiện Quy định đo trọng lực chi tiết ở Việt Nam.

Khối lượng vật chất địa hình lồi lõm xung quanh điểm trọng lực so với mặt phẳng nằm ngang đi qua điểm này cũng là một dạng khối lượng vật chất cần loại bỏ, đặc biệt ở các khu vực rừng núi nhờ số hiệu chỉnh Faye. Vấn đề tiếp theo là xây dựng phương pháp triển khai tính toán số hiệu chỉnh Faye (1) dựa trên mạng lưới (grid) các ô chuẩn hình vuông của mô hình số địa hình DTM.

Tuy nhiên, ở các khu vực rừng núi với địa hình hiểm trở, núi cao suối sâu, bản thân số hiệu chỉnh Faye hoặc không thể lấp đầy khối lượng vật chất địa hình lõm bằng khối lượng vật chất địa hình lồi, ví dụ tại điểm trọng lực $\mathrm{P}_{1}$ trên Hình 1 và dẫn đến việc thiếu khối lượng vật chất hoặc không thể khắc phục sự thừa khối lượng vật chất địa hình lồi để lấp đầy khối lượng địa hình lõm, ví dụ tại điểm trọng lực $\mathrm{P}_{2}$ trên hình (xem hình 1).

Việc thiếu hoặc thừa các khối lượng vật chất địa hình xung quanh điểm trọng lực làm dị thường Faye biến đổi không "trơn", tức không phải là hàm điều hòa và giải tích. Để khắc phục vấn đề nêu trên, trong các tài liệu (Forsberg, R. and C.C. Tsherning (1981); Forsberg $R$. (1984)) đã đề xuất phương pháp Mô hình mặt đất còn dư (Residual Terrain Model RTM) để triển khai lý thuyết của Molodenskii M.X. trong thực tế, theo đó thay mặt địa hình thực bằng mặt địa hình trung bình của Trái đất hay còn được gọi là mặt quy chiếu. Như vậy chúng ta lại phải giải quyết bài toán xác định dị thường RTM trong việc xây dựng cơ sở dữ liệu (CSDL) trọng lực quốc gia phục vụ việc xây dựng mô hình quasigeoid quốc gia độ chính xác cao.

Các vấn đề được trình bày ở trên sẽ được nghiên cứu giải quyết trong bài báo khoa học này nhằm định hướng xây dựng CSDL trọng lực quốc gia ở Việt Nam.

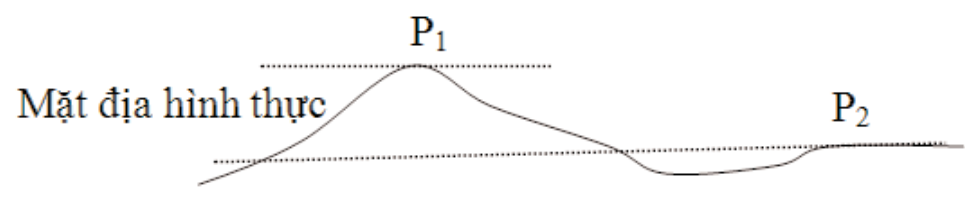

Hình 1: Các điểm $P_{1}$ và $P_{2}$ trên mặt địa hình thực 


\section{Giải quyết vấn đề}

\subsection{Hiệu chỉnh ảnh hưởng của khối lượng vật chất khí quyển trong dị thường không khí tự do}

Đối với điểm trọng lực $\mathrm{P}$ bất kỳ nằm trên mặt vật lý Trái đất, dị thường không khí tự do của điểm này được tính theo công thức:

$$
\Delta g_{k k t d}=g_{P}-\gamma_{N},
$$

ở đây $g_{P}$ - giá trị gia tốc lực trọng trường đo được tại điểm $\mathrm{P}, \gamma_{N}$ - gia tốc lực trọng trường chuẩn tại điểm $\mathrm{N}$ tương ứng với điểm $\mathrm{P}$ và nằm trên mặt telluroid (xem hình 2), thêm vào đó $\left.\gamma_{N}=\gamma_{0}-0,308562 \cdot(1+0,0007 \cdot \cos 2 B) \cdot H_{P}^{\gamma}+0,0723 x 10^{-6} \cdot\left(H_{P}^{\gamma}\right)^{2}+\left(\delta \gamma_{a}\right)_{P}<m G a l\right\rangle$,

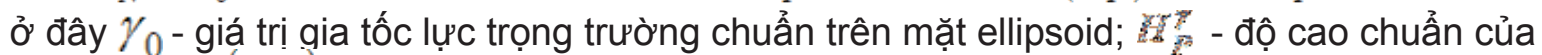
điểm $\mathrm{P}$, còn $\left(\delta \gamma_{a}\right)_{P}$ - số hiệu chỉnh vào gia tốc lực trọng trường chuấn do sự hấp dẫn của khối lượng vật chất khí quyển.

Đối với các ellipsoid WGS84, PZ-90.11, theo các tài liệu (Dimitrijevich I.J. (1987);Gravity station data format \& anomaly computations; Parametry Zemli 1990 (PZ-90.11)):

$$
\left(\delta \gamma_{a}\right)_{P}=-0,87 \cdot e^{-0,116 \cdot\left(H_{P}^{\gamma}\right)^{1,047}}<m G a l>\text {. }
$$

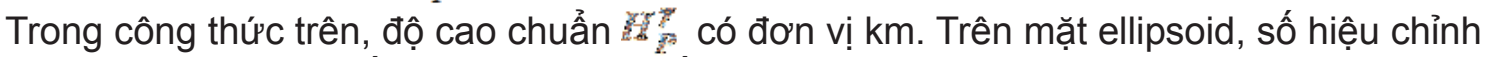
$\left(\delta \gamma_{a}\right)_{P}=-0,87 \mathrm{mGal}$. Số hiệu chỉnh này bằng $0 \mathrm{khi} \mathrm{Yr}_{\mathrm{z}}=35 \mathrm{~km}$.

Tương tự đối với các ellipsoid WGS84, PZ-90.11, theo các tài liệu (Kuroishi I., 1995; Martínez W., Sánchez L. (2001); Gruber, T., T. Peters, L. Zenner (2007)) chúng ta sử dụng công thức đa thức bậc hai ở dạng sau:

$$
\left(\delta \gamma_{a}\right)_{P}=-\left[0,8658-9,727 \cdot 10^{-5} \cdot H_{P}^{\gamma}+3,482 \cdot 10^{-9} \cdot\left(H_{P}^{\gamma}\right)^{2}\right]<m G a l>,
$$

ở đây độ cao chuẩn có đơn vị mét $(\mathrm{m})$.

Tại một số khu vực núi cao ở Việt Nam, khi lưu ý độ chính xác của gia tốc lực trọng trường đạt ở mức $\pm 1 \mathrm{mGal}$, từ bảng (xem bảng 1 ) ở dưới đây chúng ta thấy rằng số hiệu chỉnh do khối lượng vật chất khí quyển là đại lượng có ý nghĩa.

\subsection{Tính số hiệu chỉnh bề mặt đất dựa trên mô hình số độ cao DTM}

Mô hình số độ cao DTM thường được lưu giữ dưới dạng một mạng lưới (grid) các ô chuẩn (cell) hình chữ nhật (hoặc hình vuông), thêm vào đó trên ô chuẩn thứ i có độ cao chuẩn trung bình $\bar{H}_{i}^{\gamma}$ và các đỉnh có hoành độ thay đổi theo giá trị tuyệt đối tăng dần từ $y_{1}$

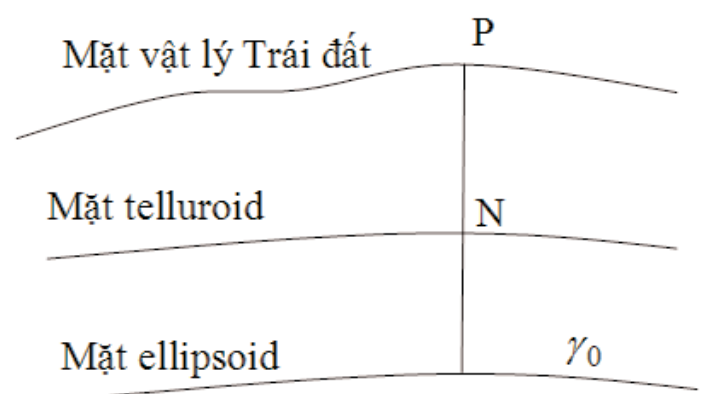

Hình 2: Quan hệ giữa điểm trọng lực $P$ trên mặt vật lý Trái đất và điểm tương ứng $N$ trên mặt telluroid 
Bảng 1

\begin{tabular}{|c|c|c|}
\hline Các vị trí địa lý & Độ cao trung bình (m) & 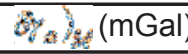 \\
\hline Tỉnh Sơn La & 700 & $-0,807$ \\
\hline Tỉnh Hà Giang & 1200 & $-0,749$ \\
\hline Cao Bằng & 1300 & $-0,739$ \\
\hline Cao nguyên Lâm Đồng & 1500 & $-0,7201$ \\
\hline Đỉnh Phan Xi Pan & 3143 & $-0,560$ \\
\hline
\end{tabular}

đến $y_{2}$, tung độ thay đổi theo giá trị tuyệt đối tăng dần từ $x_{1}$ đến $x_{2}$. Điểm trọng lực $\mathrm{P}$ có các tọa độ phẳng $x_{P}, y_{P}$ (xem hình 3 ) và độ cao chuẩn $y_{y_{F}}$.

Bốn đỉnh của ô chuẩn lần lượt có các tọa độ phẳng là $x_{1}, y_{1} ; x_{2}, y_{1} ; x_{2}, y_{2}$ và $x_{1}, y_{2}$. Bây giờ chúng ta tạo hệ tọa độ phẳng ${ }^{p}{ }^{p}$ y. với gốc tọa độ là điểm trọng lực $\mathrm{P}$. Ký hiệu các tọa độ của 4 điểm ở dạng $\xi_{1}=x_{1}-x_{P}, \xi_{2}=x_{2}-x_{P}, \eta_{1}=y_{1}-y_{P}, \eta_{2}=y_{2}-y_{P}$. Khi đó trong hệ tọa độ phẳng $\xi^{p}$ y bốn đỉnh của ô chuẩn lần lượt có các tọa độ phẳng là $\xi_{1}, \eta_{1} ; \xi_{2}, \eta_{1} ; \xi_{2}, \eta_{2}$ và $\xi_{1}, \eta_{2}$. Chúng ta ký hiệu $r=\sqrt{\xi^{2}+\eta^{2}}$ là khoảng cách từ điểm tính toán $\mathrm{P}$ đến đỉnh bất kỳ của ô chuẩn. Để tiện tính tích phân, chúng ta sắp xếp ô chuẩn thứ i sao cho theo trục tọa độ $\xi: \xi_{\min }=\xi_{1}, \xi_{\max }=\xi_{2}$, theo trục tọa độ

$\eta: \eta_{\min }=\eta_{1}, \quad \eta_{\max }=\eta_{2}$.

Như vậy, đối với ô chuẩn thứ $\mathrm{i}(\mathrm{i}=1,2, \ldots, \mathrm{n})$,ở đây $\mathrm{n}$ là tổng số các ô chuẩn tham gia tính toán số hiệu chỉnh bề mặt đất, theo tài liệu (Forsberg, R. and C.C. Tsherning (1981)), từ công thức (1) chúng ta tính được thành phần ${ }_{x_{N}}$ của số cải chính bề mặt $\delta g_{F}$ theo công thức:

$$
\left(\delta g_{F}\right)_{i}=\frac{-G \cdot \sigma_{c r} \cdot\left(\overline{\bar{H}}_{i}^{\gamma}-H_{P}^{\gamma}\right)^{2}}{2} \|\left.\left.\cdot \frac{r}{\xi \cdot \eta}\right|_{\xi_{1}} ^{\xi_{2}}\right|_{\eta_{1}} ^{\eta_{2}} \text { ở đây } G \cdot \sigma_{c r}=0,0178203276 \frac{m G a l}{m} .
$$

Số hiệu chỉnh bề mặt đất đối với tất cả $\mathrm{K}$ các ô chuẩn tham gia tính toán được xác định theo công thức:

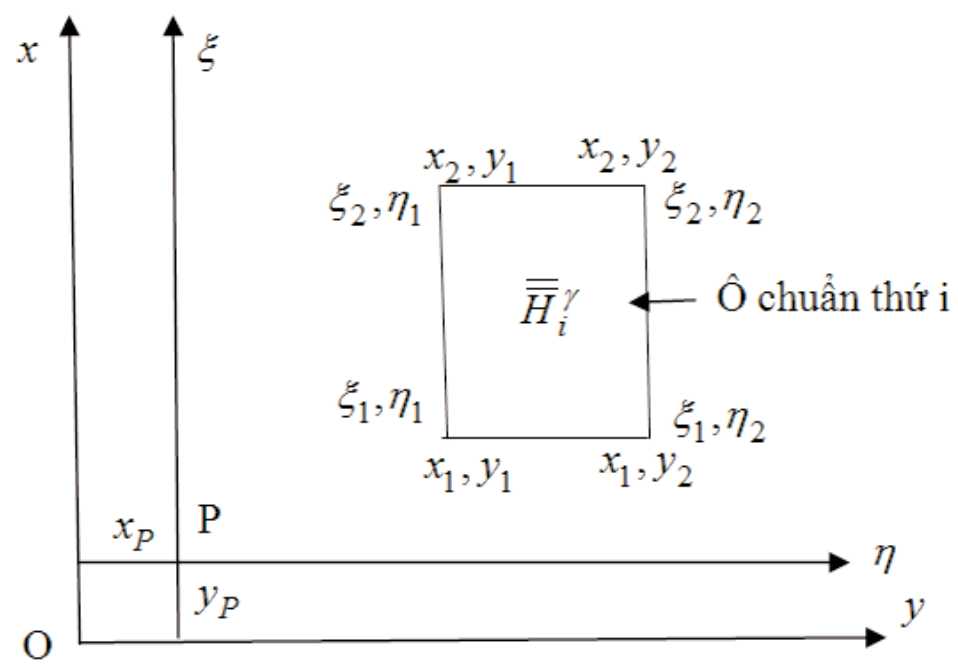

Hình 3: Tích phân mặt phẳng 


$$
\delta g_{F}=\sum_{i=1}^{K}\left(\delta g_{F}\right) .
$$

Công thức (2) đã được sử dụng để tính các số hiệu chỉnh bề mặt đất $\delta g_{F}$ trong quá trình xây dựng CSDL dị thường trọng lực RTM để thành lập mô hình trọng trường Trái đất EGM96 (Lemoine F.G., Kenyon S.C., Factor J.K., Trimmer R.G., Pavlis N.K., Chinn D.S., Cox C.M., Klosko S.M. , Luthcke S.B. , Torrence M.H. , Wang Y.M., Williamson R.G., Pavlis E.C., Rapp R.H. and T. R. Olson T.R. (1998)).

Một phương pháp khác được sử dụng rộng rãi hiệu nay để tính số hiệu chỉnh bề mặt đất là phương pháp tích phân lăng trụ được đề xuất trong các tài liệu (Nagy $D$. (1966); Nagy D., Papp G., Benedek J. (2000)). Chúng ta xây dựng hệ tọa độ không gian với gốc tọa độ là điểm trọng lực $\mathrm{P}$, trục $\Re^{2} \xi$ song song với trục $\mathrm{x}$ của hệ tọa độ phẳng quốc gia, trục Pry song song với trục y của hệ tọa độ phẳng quốc gia, trục $P z$ hướng xuống dưới theo phương của đường dây dọi (xem hình 4).

Giả sử khối lượng vật chất địa hình với ô chuẩn $A B C D$ (ô chuẩn thứ i, $\mathrm{i}=1,2, \ldots, \mathrm{K}$ ) tạo thành hình lăng trụ $\mathrm{ABCDEFGH}$. Chúng ta ký hiệu $x_{P}, x_{P}, H_{P}^{\gamma}$ là các tọa độ phẳng và độ cao chuẩn của điểm trọng lực $\mathrm{P}$. Đối với ô chuẩn $\mathrm{ABCD}$, các đỉnh $A\left(x_{1}, y_{2}\right), B\left(x_{1}, y_{1}\right)$, $C\left(x_{2}, y_{1}\right), D\left(x_{2}, y_{2}\right)$ có các tọa độ trong hệ tọa độ phẳng $O x y$ được chuyển về hệ tọa độ phẳng $P \xi \eta$ theo công thức: $\xi_{1}=x_{1}-x_{P}, \xi_{2}=x_{2}-x_{P}$,

$$
\eta_{1}=y_{1}-y_{P}, \eta_{2}=y_{2}-y_{P} \text {. }
$$

Để tiện tính tích phân lăng trụ, chúng ta sắp xếp ô chuẩn thứ i sao cho theo trục tọa độ $\xi: \xi_{\min }=\xi_{1}, \xi_{\max }=\xi_{2}$ theo trục tọa độ $\eta: \eta_{\min }=\eta_{1}, \eta_{\max }=\eta_{2}$.

Khi ký hiệu $\bar{x}$ : là độ cao chuẩn trung bình của ô chuẩn $\mathrm{ABCD}$, dựa trên tích phân lăng trụ trong tài liệu ( Sansó F. and Rummel R. (1997)) đã đưa ra công thức:

$$
\left(\delta g_{F}\right)_{i}=G \cdot \sigma_{c r}\|\| \xi \cdot \ln (\eta+l)+\eta \cdot \ln (\xi+l)-\left.\left.z \cdot \arctan \frac{\xi \cdot \eta}{z \cdot l}\right|_{\xi 1} ^{\xi_{2}}\left|\eta_{\eta_{1}}\right| z_{1}\right|_{z_{1}} ^{z_{2}},
$$

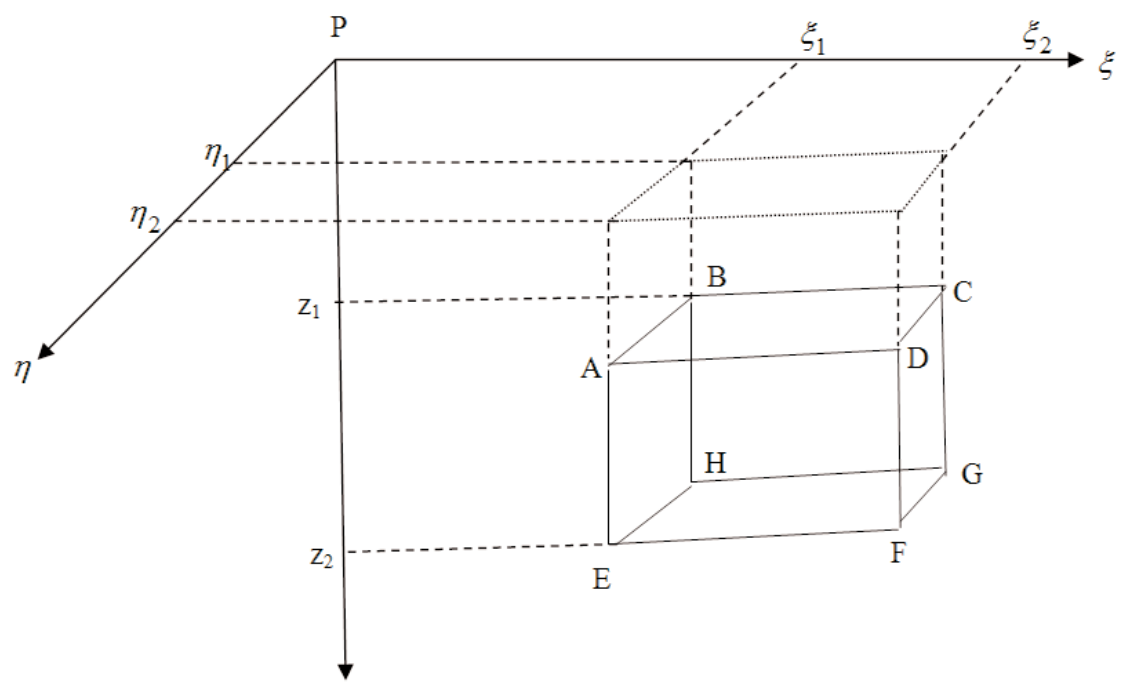

Hình 4: Tích phân lăng trụ 
Ở đây $z_{1}=0, z_{2}=H_{P}^{\gamma}-\bar{H}_{i}^{\gamma}$.

Số hiệu chỉnh bề mặt đất $\delta g_{F}$ đối với tất cả $\mathrm{K}$ các ô chuẩn tham gia tính toán được xác định theo công thức (2).

Để giảm sự phức tạp và thời gian tính toán khi tính toán theo công thức (3), trong tài liệu (Forsberg R. (1984)) đã đề xuất công thức xấp xỉ được cải biên từ công thức (3), theo đó khối lượng vật chất của lăng trư được cô đặc thành một lớp vật chất đi qua tâm của lăng trụ ở độ cao trung bình $z_{m}=\frac{z_{1}+z_{2}}{2}$. Khi đó công thức (3) được cải biên dưới dạng:

$$
\left(\delta g_{F}\right)_{i}=\left.\left.G \cdot \sigma_{c r} \cdot\left(z_{2}-z_{1}\right) \cdot\left|\xi \cdot \ln (\eta+l)+\eta \cdot \ln (\xi+l)-z_{m} \cdot \arctan \frac{\xi \cdot \eta}{z_{m} l}\right|\right|_{\xi_{1}} ^{\xi_{2}}\right|_{\eta_{1}} ^{\eta_{2}},
$$

Ở đây khoảng cách $l=\sqrt{\xi^{2}+\eta^{2}+z_{m}^{2}}$.

Trong tài liệu (Forsberg R. (1984)) đã kết luận rằng trong thực tế tính toán công thức trên có sai số nhỏ bỏ qua.

\subsection{Dị thường trọng lực RTM}

Chúng ta hoàn toàn có thể sử dụng mô hình số địa hình độ phân giải cao làm mặt địa hình thực (chưa bị làm trơn), còn sử dụng mô hình số địa hình độ phân giải thấp hơn được làm trơn là mặt quy chiếu hay còn được gọi là mặt địa hình trung bình (xem hình 1). Trong thực tế, mô hình mặt địa hình thực được đặc trưng bởi mô hình số địa hình DTM có độ phân giải cao, còn mặt địa hình trung bình được làm trơn được đặc trưng bởi mô hình số địa hình DTM có độ phân giải thấp hơn. Khi xây dựng mô hình trọng trường Trái đất EGM2008, theo tài liệu (Pavlis N.K., Factor J.K. and Holmes S.A. (2007)), mặt địa hình trung bình được tạo bởi mô hình địa hình mặt đất toàn cầu DTM2006.0 độ phân giải 5 ' $x$ 5' và 2' x 2'. Mặt địa hình thực được tạo bởi mô hình địa hình mặt đất toàn cầu DTM 2006.0 độ phân giải giải 30" x 30" (mô hình này được xây dựng dựa trên các dữ liệu SRTM và được khai triển điều hòa đến bậc 360 ). Dị thường trọng lực RTM được sử dụng để khai triển các hệ số điều hòa của thế trọng trường Trái đất đến mức 2160.

Khi sử dụng mặt địa hình thực tương ứng với mô hình số địa hình có độ phân giải cao để xác định dị thường không khí tự do, chúng ta phải sử dụng độ cao chuẩn chi tiết $H_{P}^{\gamma}$ của điểm trọng lực $\mathrm{P}$ trên mặt địa hình thực. Khi sử dụng mặt địa hình trung bình tương ứng với mô hình số địa hình có độ phân giải trung bình để xác định dị thường không khí tự do,

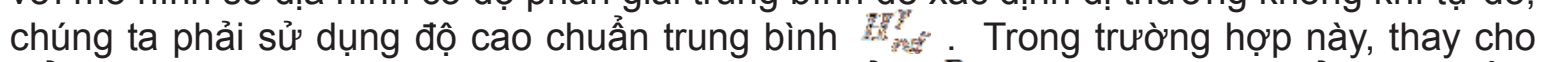
điểm $\mathrm{P}$ trên mặt địa hình thực chúng ta sử dụng điểm $P_{r e f}$ tương ứng với điểm $\mathrm{P}$ và nằm trên mặt địa hình trung bình. Điểm $\mathrm{N}_{\text {ref }}$ nằm trên telluroid trái đất trung bình tương ứng với điểm $\dot{P}_{\text {ref }}$, thêm vào đó telluroid trái đất trung bình được xác định nhờ độ cao được làm

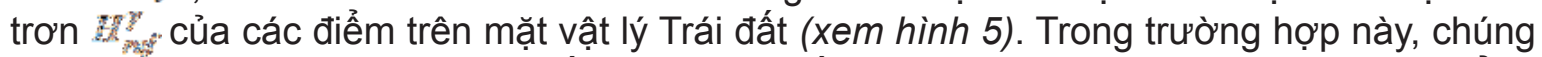
ta phải loại bỏ ảnh hưởng của khối lượng vật chất địa hình giữa địa hình thực và mặt phẳng đi qua điểm $\mathrm{P}_{\text {ref }}$ trong giá trị gia tốc lực trọng trường được đo tại điểm $\mathrm{P}$ và ở lần xấp xỉ thứ nhất chúng ta coi giữa điểm $\mathrm{P}_{\text {ref }}$ và điểm $\mathrm{N}_{\text {ref }}$ là không khí tự do và dị thường không khí tự do được tính theo độ cao chuẩn $\bar{H}_{\text {ref }}^{\gamma}$. Thuật ngữ "mặt telluroid địa hình trung bình" được sử dụng để chỉ mặt telluroid tương ứng với mặt địa hình trung bình.

Khi di chuyển điểm $\mathrm{P}$ trên mặt địa hình thực theo đường vuông góc với mặt ellipsoid đi một đoạn $\Delta H=H_{P}^{\gamma}-H_{\text {ref }}^{\gamma}$ đến điểm $\mathrm{P}_{\text {ref }}$ trên mặt địa hình trung bình, điểm $\mathrm{N}$ (tương ứng 
với điểm $\mathrm{P}$ ) trên telluroid địa hình thực được di chuyển đi một đoạn $\Delta H=H_{P}^{\gamma}-H_{\text {ref }}^{\gamma}$ đến điểm $\mathrm{N}_{\text {ref }}$ trên telluroid địa hình trung bình. Do đoạn $\mathrm{PQ}_{0}$ bằng độ cao trắc địa $H_{P}=H_{P}^{\gamma}+\zeta_{P}=H_{r e f}^{\gamma}+\zeta_{P}+\Delta H$, nên chúng ta thấy rằng đoạn $\mathrm{PN}$ bằng đoạn $\mathrm{P}_{\text {ref }} \mathrm{N}_{\text {ref }}$ và bằng dị thường độ cao $\zeta_{P}$. Điều này có nghĩa là trong trường hợp sử dụng mặt địa hình trung bình thay cho mặt địa hình thực, giá trị dị thường độ cao đều không đổi và bằng $\bar{\zeta}_{P}$

Chúng ta có thể làm kết luận sau: Việc thay mặt địa hình thực bằng mặt địa hình trung bình không làm thay đổi giá trị dị thường độ cao được xác định theo cách tiếp cận của Molodenxkii M.X.. Tuy nhiên, như đã trình bày ở trên, ưu điểm nổi trội của phương pháp RTM là cho phép loại bỏ được ảnh hưởng của sự nhiễu của khu vực địa hình hiểm trở với nhiều núi cao, vực sâu đến giá trị dị thường trọng lực không khí tự do. Việc loại bỏ khối lượng vật chất địa hình giữa mặt địa hình thực và mặt địa hình được làm trơn (mặt địa hình trung bình) sẽ làm dị thường trọng lực RTM trở thành hàm điều hòa. Khi đó, dị thường trọng lực RTM được xác định theo công thức (Forsberg R. (1984)):

$$
\Delta g_{R T M}=\Delta g_{F}-2 \pi \cdot G \cdot \sigma_{c r} \cdot\left(H_{P}^{\gamma}-H_{r e f}^{\gamma}\right),
$$

ở đây $\Delta g_{F}$ - dị thường Faye.

Dị thường trọng lực RTM đã được sử dụng để xây dựng các mô hình EGM96, mô hình EGM2008 (Lemoine F.G., Kenyon S.C., Factor J.K., Trimmer R. G., Pavlis N.K., Chinn D.S., Cox C.M., Klosko S.M. , Luthcke S.B. , Torrence M.H. , Wang Y.M., Williamson R.G., Pavlis E.C., Rapp R.H. and T. R. Olson T.R. (1998); Pavlis N.K., Factor J.K. and Holmes S.A. (2007)), mô hình geoid OSGM02 của Vương quốc Anh (Forsberrg, R., G. Strykowski, J.C. Ileffe, M. Ziebart, Ch. Tschening, P. Cruddase (2001)), mô hình quasigeoid GCG05 của Cộng hòa liên bang Đức (Hirt C. (2011)) v.v...

Theo tài liệu (Roman, D. R., Y.M. Wang, J. Saleh, X. Li, W. Waickman (2009), đối với nước Mỹ lần đầu tiên trong lịch sử Tổ chức Đo đạc trắc địa quốc gia (NGS) đã từ bỏ dị thường trọng lực Helmert và chuyển sang sử dụng dị thường trọng lực RTM để xây dựng mô hình geoid quốc gia USGG2009 độ phân giải 1'x 1' của nước Mỹ.

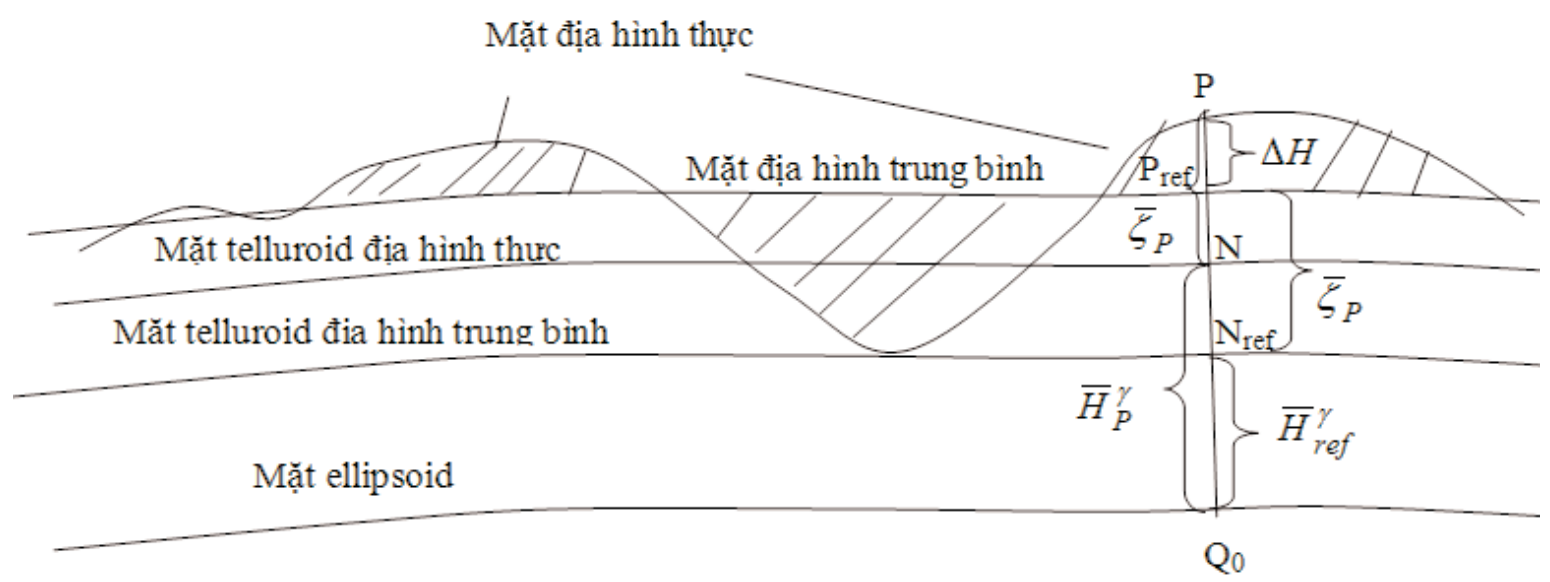

Hình 5: Quan hệ giữa mặt địa hình thực và mặt địa hình trung bình 


\section{Kết luận}

Với việc phát triển mạnh mẽ của công tác đo đạc trọng lực chi tiết ở Việt Nam hiện nay cùng với lợi thế của nước đi sau, việc tiếp thu các thành tựu hiện đại của các nước phát triển trong việc xây dựng CSDL dị thường trọng lực hiện đại và xây dựng mô hình quasigeoid quốc gia và toàn cầu độ chính xác cao là rất cấp bách để hoàn thiện các quy chuẩn quốc gia liên quan đến việc xây dựng CSDL dị thường trọng lực quốc gia.

Trong bài báo khoa học này đã nghiên cứu và đề xuất bổ sung vào "Quy định đo trọng lực chi tiết" các nội dung liên quan đến việc hiệu chỉnh dị thường trọng lực không khí tự do bởi các số hiệu chỉnh do khối lượng vật chất khí quyển và do khối lượng vật chất giữa mặt địa hình thực và mặt địa hình trung bình. Ngoài ra, với việc sử dụng mô hình số độ cao độ phân giải cao, phương pháp tính toán hiệu quả các số hiệu chỉnh Faye là phương pháp Forsberg, R. - C.C. Tsherning và phương pháp tích phân lăng trụ của Nagy D..O

\section{Tài liệu tham khảo}

[1]. Dimitrijevich I.J. (1987). WGS84 Ellipsoidal Gravity formula and Gravity Anomaly Conversion Equations. Pamphlet, Department of Defense Gravity Services Branch, Defense Mapping Agency AeroSpace Center, St. Louis, Missoury.

[2]. Forsberg, R. and C.C. Tsherning (1981). The use of height data in gravity field aproximation by collocation. Journal Geophys. Res., 86, No.9, pp. 7843 - 7854.

[3]. Forsberg R. (1984). A study of terain reduction, density anomalies and geophysical inversion methods in gravity field modelling. Repot 355, 134 p, April 1984, Department of Geodetic Science and Surveying. Ohio State University. Columbus.

[4]. Forsberg R., Strykowski G., Iliffe J.C., Ziebart M., Cross P.A., Tscherning C.C., Cruddace P. (2001). OSGM02: A new geoid model of the British Isles. www.discovery.ucl.ac.uk>... >UCL.DISCOVERY

[5]. Gravity station data format \& anomaly computations. National Imagery and Mapping Agency. Department of Geodesy and Geophysics. 30 July 1999, 7p.

[6]. Gruber, T., T. Peters, L. Zenner (2007). The Role of the Atmosphere for Satellite Gravity Field Mission. IUGG General Assembly, Session G2, Perugia, 2 - 13/07/2007.

[7]. Hà Minh Hòa (2014). Lý thuyết và thực tiễn của Trọng lực trắc địa. Nhà Xuất bản Khoa học và Kỹ thuật, 592 trg., Hà Nội - 2014.

[8]. Hirt C. (2011). Assessment of EGM2008 over Germany using accurate quasigeoid heights vertical deflections, GCG05 and GPS/leveling. Zeitschrift für Geodäsie, Geoinformation und Landmanagement (zfv) 136 (3): 138 - 149.

[9]. Kuroishi I., 1995. Precise gravimetric determination of geoid in the vicinity of Japan. Bull. Geographical Surv. Inst., 41, 1-94.

[10]. Lemoine F.G., Kenyon S.C., Factor J.K., Trimmer R.G., Pavlis N.K., Chinn D.S., Cox C.M., Klosko S.M. , Luthcke S.B. , Torrence M.H. , Wang Y.M., Williamson R.G., Pavlis E.C., Rapp R.H. and T. R. Olson T.R. (1998). The Development of the Joint NASA GSFC and NIMA Geopotential Model EGM96, NASA Goddard Space Flight Center, NASA Technical Report NASA/TP-1996l8-206861 Greenbelt, Maryland, 20771 USA, July 1998). 
[11]. Martínez W., Sánchez L. (2001). Improving the Quasigeoid Model in Colombia. In: Drewes H., Dodson A., Fortes L.P.S., Sánchez L., Sandoval P. Vertical Reference Systems. International Association of Geodesy Symposia, Volume 124, IAG

[12]. Moritz H. (1980). Advanced Physical Geodesy. Herbert wichmann Verlag Karlsruhe, Abacus Press Tunbridge Wells Ken ${ }^{\top}, 512 \mathrm{p}$.

[13]. Moritz H. (1984). Geodetic Reference System 1980. Bulletin Geodesique, 58 (3), $388-329$.

[14]. Nagy D. (1966). The Prism method for terrain corrections using digital computers. Pure and Applied Geophysics. Vol. 63, Issue 1, pp. 31-39. DOI:10.1007/BF00875156, Birkhäuser Verlag 1966.

[15]. Nagy D., Papp G., Benedek J. (2000). The gravitational potential and its derivaties for the prism. Journal of Geodesy, 74(7-8): 552-560. DOI: 10.1007/s001900000116.

[16]. NGA.STND.0036_1.0.0_WGS84. National Geospatial - Intelligence Agency (NGA) Standardization Document. Department of Defence, World Geodetic System 1984 - Its Definition and Relationships with Local Geodetic System, 2014 - 07- 08, Version 1.0.0., 207 p.

[17]. Parametry Zemli 1990 (PZ-90.11). Reference Ducument. Military Topographic Department of the General Staff of Armed Forces of the Russian Federation. Moscow2014. $51 \mathrm{p}$.

[18]. Pavlis N.K., Factor J.K. and Holmes S.A. (2007). Terrain - related Gravimetric Quantities Computed for the Next EGM. Proceedings of the 1st International Symposium of the International Gravity Field Service (IGFS), Istanbul, pp. 318-323.

[19]. Quy định đo trọng lực chi tiết. Thông tư số 08/2012/TT-BTNMT ngày 08/08/2012 của Bộ trưởng Bộ Tài nguyên và Môi trường.

[20]. Roman, D. R., Y.M. Wang, J. Saleh, X. Li, W. Waickman (2009). USGG2009 \& GEOID09: New geoid height models for surveying/GPS. NOAA's National Geodetic Survey, ACSM - MARLS - UCLS - WFPS Conference 2009, 20 February 2009, Salt Lake City, UT.

[21]. Sansó F. and Rummel R. (1997). Lecture Notes in Earth Sciences: GBVP in view of the One Centimeter Geoid. Springer, New York. O

\section{Summarry}

\section{Perfection of procedure of gravimetric data processing for construction of gravi- ty anomaly database in Vietnam}

\section{Ha Minh Hoa, Vietnam Institute of Geodesy and Cartography}

This scientific article displays obtained research results in the World and proposals additions to the state standards about ditailed gravimetric measurements with some contents related to correction of the air - free anomalies by corrections of the atmosphric masses and masses between the real topographic surface and mean topographic surface. Beyond that, this article proposes using method of the prism integral for calculation of the Faye corrections. O 